\title{
Distribution of Fumonisins in Maize Ears Infected with Strains of Fusarium moniliforme that Differ in Fumonisin Production
}

\author{
Anne E. Desjardins and Ronald D. Plattner, Mycotoxin Research Unit, USDA Agricultural Research Service, \\ National Center for Agricultural Utilization Research, Peoria, IL 61604; and Ming Lu and Larry E. Claflin, Plant \\ Pathology Department, Kansas State University, Manhattan 66506
}

\begin{abstract}
Desjardins, A. E., Plattner, R. D., Lu, M., and Claflin, L. E. 1998. Distribution of fumonisins in maize ears infected with strains of Fusarium moniliforme that differ in fumonisin production. Plant Dis. 82:953-958.

Strains of Fusarium moniliforme (Gibberella fujikuroi mating population A) that differ in fumonisin production in vitro were previously identified in a Kansas field population. One strain that produced high levels of fumonisins and two strains that produced very low levels of fumonisins were applied to maize kernels at planting at the Rocky Ford Farm near Manhattan, Kansas. The distribution of fumonisins in symptomatic and symptomless kernels from individual harvested ears was determined by high performance liquid chromatography, and the distribution of the three applied strains in the kernels was determined by vegetative compatibility group analysis. Both symptomatic and symptomless kernels were extensively colonized with $F$. moniliforme, but the highest levels of fumonisins were in the symptomatic kernels. All three applied strains were recovered from kernels in 1993, and two of them were recovered from kernels in 1994. However, a high frequency of ear and kernel infection with a strain that produced little fumonisin in vitro did not consistently decrease the level of fumonisins. The frequency of infection with fumonisin low-producing strains may have been too low for competitive exclusion of naturally occurring fumonisin high-producing strains. Also, strains that are low-fumonisin producers under laboratory conditions may be high producers in the field.
\end{abstract}

Fusarium moniliforme Sheldon (sexual stage Gibberella fujikuroi (Sawada) Ito in Ito \& K. Kimura) mating population A is a common pathogen of maize, causing root, stalk, and ear rots worldwide $(8,12)$. Ear rot caused by $F$. moniliforme mating population A can cause serious problems for the maize feed and food industries by contaminating grain with fumonisins, a class of mycotoxins first identified in 1988. Fumonisins inhibit the biosynthesis of sphingolipids, changing the sphingolipid composition of a number of target tissues, and can cause a variety of diseases in animals that eat contaminated feeds. Purified fumonisins have been shown to cause leukoencephalomalacia in horses, pulmonary edema in pigs, and liver cancer in rats. Consumption of maize contaminated with high levels of fumonisins has been epidemiologically associated with high levels of

Corresponding author: Anne E. Desjardins E-mail: desjarae@mail.ncaur.usda.gov

Research was partially supported by the Kansas Corn Commission and the Kansas Agricultural Experiment Station, Contribution No. 98-172-J.

Accepted for publication 15 May 1998.

Publication no. D-1998-0615-04R

This article is in the public domain and not copyrightable. It may be freely reprinted with customary crediting of the source. The American Phytopathological Society, 1998. esophageal cancer in human populations in parts of the world where maize is a staple food (12).

The surveillance and control of fumonisins and other mycotoxins in food and feed grains require collection and analysis of samples that are representative of the material being tested. It is well-established that the distribution of aflatoxins is highly skewed in individual maize ears infected with Aspergillus flavus (3,21). Also, in maize ears experimentally infected with $F$. graminearum, deoxynivalenol levels can be up to 200 times higher in symptomatic kernels than in symptomless kernels $(1,17)$. The distribution of fumonisins in individual ears of maize infected with F. moniliforme has received little attention. To date, studies of the fumonisin levels of symptomatic and symptomless maize have measured bulked ears or shelled kernels (22). Rheeder et al. (18) compared fumonisin levels in bulked ears of good quality maize and visibly moldy maize collected from farm households in the Transkei region of southern Africa. Low fumonisin levels (up to $2 \mu \mathrm{g} / \mathrm{g}$ ) were found in good quality samples, but fumonisin levels were 14 to 30 times higher in samples with visible mold. In contrast, in farm households in China, Chu and Li (2) found high fumonisin levels (30 to $40 \mu \mathrm{g} / \mathrm{g}$ ) in samples of shelled kernels with no visible mold contamination, and only two- to threefold higher levels in samples with heavy mold contamination. Furthermore, few studies have investigated the relationship between levels of fumonisins and incidence of infection by fumonisin-producing Fusarium spp. in maize, and some of these studies have produced contradictory results $(18,19)$. These discrepancies may reflect the fact that $F$. moniliforme is not only a major pathogen of maize, but is also widely distributed in symptomless maize plants, and can be isolated from apparently healthy tissue of the root, stalk, leaves, and ear (12). Thus, the relationships between fungal infection, visible disease symptoms, and fumonisin levels are not well-defined.

Although the great majority of naturally occurring strains of $F$. moniliforme produce high levels of fumonisins, extensive strain surveys have identified variants with fumonisin nonproduction or low-production phenotypes $(9,10)$. Maize collected in Kansas yielded two strains, A-1175 and A1324 , that produce little or no fumonisins on maize-meal culture medium under laboratory conditions (16). Kedera et al. (7) and Munkvold and coworkers $(11,13)$ have demonstrated that strains of $F$. moniliforme applied to maize kernels at planting can be recovered in ears harvested from mature plants. These data support the hypothesis that maize plants can be systemically colonized with one strain, or a few strains, of $F$. moniliforme. If fumonisin nonproducing or low-producing strains can systemically infect maize and competitively exclude fumonisin-producing strains, then fumonisin levels in kernels at maturity may be reduced.

The objectives of the present study were (i) to determine the distribution of fumonisins in symptomatic and symptomless kernels from individual maize ears, and (ii) to determine the ability of fumonisin lowproducing strains of $F$. moniliforme applied to kernels at planting to systemically infect maize plants and to reduce fumonisin contamination of the harvested ears under field conditions.

\section{MATERIALS AND METHODS}

Inoculum preparation and field plots. The three applied strains were genetically fertile members of $G$. fujikuroi mating population A. Strain A-501 was isolated from maize in Rossville, Kansas; strain A1175 from maize in Hillsboro, Kansas; and strain A-1324 from sorghum in Enosdale, Kansas. Seeds of maize inbred lines LH82 
and LH132 (Holden Foundation Seeds, Williamsburg, IA) were disinfested by placing in sterile distilled water at room temperature for $4 \mathrm{~h}$, in $55^{\circ} \mathrm{C}$ water for 5 min, and in cool water for a few seconds, followed by air-drying overnight (6). Hotwater-treated seeds were found to be free of Fusarium spp. when they were surface disinfested by placing in $0.5 \% \mathrm{NaOCl}$ for 1 min, rinsed twice in sterile water, and tested by plating a representative sample of halved seeds on a Fusarium-selective medium (15). Spore suspensions $\left(10^{5}\right.$ macroconidia and microconidia/ml) were prepared from $F$. moniliforme strains A-501, A-1175, and A-1324 grown on modified Czapek-Dox complete medium (4). Hotwater-treated seeds (150 of each inbred line) were shaken for $30 \mathrm{~min}$ in a $250-\mathrm{ml}$ flask with $5 \mathrm{ml}$ spore suspension, then allowed to dry overnight. Treated seeds were surface disinfested by placing in $0.5 \% \mathrm{NaOCl}$ for $1 \mathrm{~min}$, and were found to be $100 \%$ infected with Fusarium spp. when they were tested by plating on a selective medium as described above.

In field tests in both 1993 and 1994, treated seeds of each inbred line were planted in a randomized complete block design, with three replicates per treatment of each inbred line, at the Rocky Ford Experimental Farm, Manhattan, Kansas. Seeds that had not been hot-water-treated were included in the 1994 field test. Each block consisted of a 5-m row with seeds planted at $23-\mathrm{cm}$ intervals, a row spacing of $76 \mathrm{~cm}$, and $1.5-\mathrm{m}$ alleys separating blocks. In 1994, treatment blocks were also separated by two rows of a maize hybrid from a cross between inbred lines LH82 and LH132. At physiological maturity, all ears from the inbred lines planted in 1993 and 1994, and randomly selected ears from the hybrid maize planted in 1994, were hand-picked, husked, air-dried for 2 weeks, and sent to Peoria, Illinois for fumonisin analysis. In 1994, microbiological analysis was conducted in Manhattan, Kansas; therefore, each ear was sampled by removing 12 seeds prior to shipment.

Each field test was designed to yield 10 ears per block with a total of 30 ears per treatment group for each inbred line. However, due to poor stand and pollination during the cool, wet summer of 1993, many of the 24 blocks planted contained fewer than 10 ears, yielding a total of 144 ears rather than the expected 240 ears. All 144 available ears were tested for recovery of applied strains, and 53 ears for fumonisin analysis were selected to represent all blocks within each treatment group as equally as possible from the ears available. In 1994, 280 ears were recovered from a potential of 300 ears from 30 blocks planted. No ears were obtained from two of the blocks. All 280 ears available were tested for recovery of applied strains. For fumonisin analysis, 109 ears were selected to represent all available blocks, with a minimum of 3 ears per block, except for ears treated with strain A-1324, where only four blocks were sampled.

Fumonisin analysis. Maize ears were hand-shelled and the kernels from each ear were separated into a symptomless fraction that contained only bright yellow kernels, and a symptomatic fraction that contained all kernels that were visibly moldy, darkened, streaked, or chalky in appearance. The resulting fractions were weighed, ground, thoroughly mixed, and frozen until analyzed. Fumonisins were analyzed by high-performance fluorescence liquid chromatography (HPLC) using a method similar to that previously described (23). Ground maize samples (typically $10 \mathrm{~g}$ ) were weighed into Erlenmeyer flasks and extracted with water:acetonitrile (1:1 vol:vol; $5 \mathrm{ml} / \mathrm{g}$ maize) for $3 \mathrm{~h}$ with occasional shaking. The extract was filtered through Whatman 2V filter paper. Sample clean-up prior to analysis was accomplished using strong-anion-exchange (SAX) solid phase extraction columns (Varian, Palo Alto, CA). A 10-ml aliquot of extract (equivalent to $2 \mathrm{~g}$ maize) was applied to the column, followed by $8 \mathrm{ml}$ methanol:water $(3: 1$ vol:vol $)$ and $3 \mathrm{ml}$ methanol. A flow rate of $<2 \mathrm{ml} / \mathrm{min}$ was maintained, and the column was not allowed to run dry. Fumonisins were eluted with $12 \mathrm{ml} 1 \%$ acetic acid in methanol which was evaporated to dryness under a stream of nitrogen at $60^{\circ} \mathrm{C}$ and resuspended in $200 \mu \mathrm{l}$ acetonitrile:water (1:1 vol:vol). The samples were stored at $4^{\circ} \mathrm{C}$ until analysis.

Samples were derivatized with orthophthalaldehyde (OPA; 23). Typically, if the fumonisin level was expected to be below $5 \mu \mathrm{g} / \mathrm{g}$ maize, then $25 \mu \mathrm{l}$ sample, $50 \mu \mathrm{l}$ OPA reagent, and $25 \mu \mathrm{l}$ methanol were measured into a reaction vial, shaken for 1 $\mathrm{min}$, and a $50-\mu \mathrm{l}$ aliquot was injected onto the HPLC column. Samples were diluted if the fumonisin level was expected to be higher: $25 \mu \mathrm{l}$ sample, $50 \mu \mathrm{l}$ reagent, and $625 \mu \mathrm{l}$ methanol were mixed, and $50 \mu \mathrm{l}$ was injected; or $25 \mu \mathrm{l}$ sample, $50 \mu \mathrm{l}$ reagent, and 1,250 $\mu \mathrm{l}$ methanol were mixed, and $10 \mu \mathrm{l}$ was injected. Analyses were performed using a PE 3 X3 ODS column, a Thermoseparations AS3000 autosampler, and a Thermoseparations FL2000 fluorescence detector. Sample peaks were identified by retention time compared with standards $\mathrm{FB}_{1}, \mathrm{FB}_{2}$, and $\mathrm{FB}_{3}$ and quantified based on the external standard using known concentrations of the compounds. The detection limits for $\mathrm{FB}_{1}, \mathrm{FB}_{2}$, and $\mathrm{FB}_{3}$ were $0.05,0.10$, and $0.10 \mu \mathrm{g} / \mathrm{g}$, respectively. A linear response at fumonisin levels from 0.05 to $>500 \mu \mathrm{g} / \mathrm{g}$ was achieved. For samples with higher fumonisin levels, the extract was diluted ten-fold, which made the overall detection limit of the system 0.05 to $5,000 \mu \mathrm{g} / \mathrm{g}$.

To assure reliability and reproducibility of the SAX clean-up procedure, extracts of a reference maize meal containing approximately $1 \mu \mathrm{g} / \mathrm{g}$ fumonisins were run as controls with every set of samples. In addition, replicate clean-up and HPLC analysis were done on randomly chosen samples. Fumonisin levels in samples generally were reproducible across the quantitation range, with a coefficient of variation of $<20 \%$. Fumonisin data obtained from the two maize inbred lines were combined after statistical analysis showed no significant differences between the inbred lines.

Recovery of applied fungal strains from maize tissues. For fungal identification from maize inbred lines LH82 and LH132, symptomless kernels were reserved from the top, middle, and bottom sections of each ear; three kernels were reserved from each ear section in 1993 and four kernels were reserved from each ear section in 1994. In order to compare strain recovery from symptomatic and symptomless tissues from the same ear, three symptomatic kernels were reserved from selected ears harvested in 1993. Each kernel was stored individually in a paper envelope at room temperature.

For ears harvested in 1993, three reserved symptomless kernels from each ear (one kernel each from the top, middle, and bottom of the ear), were tested for the presence of $F$. moniliforme, and all isolates obtained were analyzed for vegetative compatibility. For ears harvested in 1994, 12 kernels from each ear (4 kernels each from the top, middle, and bottom of the ear) were tested for the presence of $F$. moniliforme, but no more than one isolate from each ear section was analyzed for vegetative compatibility. Kernels were surface-disinfested by placing in $0.5 \%$ $\mathrm{NaOCl}$ for $1 \mathrm{~min}$, rinsed twice in sterile water, and softened in sterile water for 1 to $2 \mathrm{~h}$. Each kernel was split open with a sterile knife, and the cut surface of each half was placed on the surface of a plate of Fusarium selective agar medium containing para-chloronitrobenzene (PCNB; 15). Kernels were incubated for 5 to 7 days, then one colony per kernel was subcultured to carnation leaf agar for identification according to Nelson et al. (15). Isolation data obtained from the two inbred maize lines were combined after statistical analysis showed no significant differences between the inbred lines.

In the 1993 field test, fungal isolates were also recovered from stems of 2-weekold seedlings and from stalks of 2-monthold maize plants. A 2- to $3-\mathrm{cm}$ segment of each seedling stem was cut above the first root, surface disinfested for $1 \mathrm{~min}$ in $0.5 \%$ $\mathrm{NaOCl}$, and rinsed with sterile water. Each stem was split, and the cut surfaces were placed on PCNB selective medium (15). A stalk segment was removed from the first node below the bottom ear of each 2month-old plant, and surface disinfested for $1 \mathrm{~min}$ in $0.5 \% \mathrm{NaOCl}$ as above. Three 
1-cm cylinders were cut from each stalk segment using a cork borer; then the tissue cylinders were cut crosswise and placed on PCNB selective medium (15). One colony per tissue sample was subcultured, identified, and analyzed for recovery of the applied strains.

To determine percent infection, isolates of $F$. moniliforme were identified by their production of microconidia in chains on carnation leaf agar (15). This trait is not sufficient to distinguish $F$. moniliforme from the closely related species $F$. proliferatum and $F$. thapsinum which can also occur on maize (8). However, it was not necessary to identify all isolates to the species level in this study, because vegetative compatibility testing was being used to determine which isolates were compatible with the applied strains.

The vegetative compatibility group identity of the isolates recovered from the maize tissues was determined by the use of nitrate-nonutilizing mutants (nits) as previously published (4). Nitrate nonutilizing auxotrophs were generated from strains A501, A-1175, and A-1324, and from the recovered field isolates, and were assigned to assigned to phenotypic classes nit 1 , nit 3 , or nit $\mathrm{M}$, based on differential growth on media with various nitrogen sources. Assignment of recovered isolates to a vegetative compatibility group was determined by the formation of robust growth in complementation tests when a nit 1 or nit 3 mutant of the isolate was paired with a nit $\mathrm{M}$ mutant of one of the applied strains. All isolates derived from maize tissues in both field tests were paired with all three applied strains.

Statistical analysis. Differences between treatments were evaluated statistically for each year in a two-stage process. First, a table was constructed for each test of ears, kernels, or strains by dividing the data into two classes: infected or not infected for ears and kernels, present or absent for each strain. An overall Chi-square test was run for each table ( $\operatorname{size}=2$ by 5 in
1993, 2 by 6 in 1994) to test for differences among treatments in incidence of infection, recovery of applied strains, and presence of detectable levels of fumonisins. If the overall Chi-square was significant at $P<$ 0.01 , the second stage of the analysis consisted of pair-wise 2 by 2 Chi-square comparisons of each pair of treatments at $P<$ 0.05 .

\section{RESULTS}

Microbiology. F. moniliforme was isolated from symptomless maize seedlings and from stalk pieces from 2-month-old plants from all treatment groups in the 1993 field test (Table 1). The mean frequency of seedling infection was $26 \% 2$ weeks after planting, and there were no significant differences among treatment groups. The mean frequency of stalk infection was $60 \% 2$ months after planting, and there were no significant differences among treatment groups. Vegetative compatibility tests showed that, among isolates from seedlings and stalks, the three applied strains, A-501, A-1175, and A-1324, were only recovered from plants to which they had been applied. The frequency of recovery of the applied strains was 43 to $78 \%$ among $F$. moniliforme isolates from 2week-old seedlings, but only 6 to $9 \%$ among isolates from 2-month-old plants.

$F$. moniliforme was isolated from symptomless maize kernels from all treatment groups in both the 1993 and 1994 field tests (Table 2). In 1993, the mean frequencies of kernel and ear infection were 62 and $83 \%$, respectively, but there were no significant differences among treatment groups. In 1994, the mean frequencies of kernel and ear infection were 33 and 70\%, respectively. In 1994, differences in kernel infection among some treatment groups were significant, but there was no consistent trend toward an increase in the frequency of symptomless kernel infection following seed treatment at planting with $F$. moniliforme. Isolates vegetatively compatible with all three ap- plied strains were recovered from symptomless kernels from plants to which they had not been applied. Following seed treatment, the frequency of isolates vegetatively compatible with strain A-501 increased to 23 and $37 \%$ of infected kernels, and to 30 and $32 \%$ of all ears tested (both infected and uninfected) in 1993 and 1994, respectively. Following seed treatment, the frequency of strain A-1175 increased to 26 and $39 \%$ of infected kernels, and to 34 and $32 \%$ of all ears tested in 1993 and 1994, respectively. Strain A-1324 showed little change in recovery frequency following seed treatment in 1993, and very poor recovery in 1994.

The frequency of infection by $F$. moniliforme in symptomatic kernels from the 1993 field test was determined for a total of 27 plants: 8 plants inoculated with A-501, 14 plants inoculated with strain A1175 , and 5 plants inoculated with strain A-1324. The purpose of this study was not a general survey, but rather a comparison of $F$. moniliforme isolates from symptomatic and symptomless kernels from the same ear. The 27 ears selected for this analysis were ears whose symptomless kernels had yielded the strain applied at planting. Three symptomatic kernels per ear were tested, and the frequency of infection ranged from 71 to $93 \%$ of the kernels, and from 86 to $100 \%$ of the ears, among the three treatment groups tested. There were no significant differences in frequencies of symptomatic kernel infection among treatment groups. Isolates obtained from the symptomatic kernels were tested against all three applied strains. Isolates vegetatively compatible with strain A-501 were recovered from symptomatic kernels from only one of eight ears tested, and strain A-1324 was not recovered from symptomatic kernels from any of the five ears tested. In contrast, strain A1175 was recovered from at least one of three sampled symptomatic kernels in 6 of 12 ears tested. The three applied strains were not recovered from sympto-

Table 1. Infection of symptomless maize seedlings and 2-month-old plants with Fusarium moniliforme and recovery of isolates vegetatively compatible with applied strains, 1993 field test ${ }^{\mathrm{y}}$

\begin{tabular}{|c|c|c|c|c|c|c|}
\hline \multirow[b]{2}{*}{ Treatment $^{\mathrm{z}}$} & \multirow[b]{2}{*}{ No. plants } & \multirow[b]{2}{*}{ Infected plants $(\%)$} & \multirow[b]{2}{*}{ No. isolates tested } & \multicolumn{3}{|c|}{ No. isolates vegetatively compatible with strain } \\
\hline & & & & A-501 & A-1175 & A-1324 \\
\hline \multicolumn{7}{|c|}{ Stalks of 2-week-old seedlings } \\
\hline Heat-treated & 17 & 6 & 1 & 0 & 0 & 0 \\
\hline A-501 & 20 & 30 & 6 & 4 & 0 & 0 \\
\hline A-1175 & 26 & 35 & 9 & 0 & 7 & 0 \\
\hline A-1324 & 26 & 27 & 7 & 0 & 0 & 3 \\
\hline \multicolumn{7}{|c|}{ Stalks of 2-month-old plants } \\
\hline Heat-treated & 18 & 50 & 15 & 0 & 0 & 0 \\
\hline A-501 & 18 & 67 & 18 & 1 & 0 & 0 \\
\hline A-1175 & 18 & 39 & 13 & 0 & 1 & 0 \\
\hline A-1324 & 18 & 83 & 23 & 0 & 0 & 2 \\
\hline
\end{tabular}


matic kernels from plants to which they had not been applied.

Fumonisin levels. Visible symptoms of Fusarium ear rot, including visibly moldy, darkened, streaked, or chalky kernels, were observed among maize ears from all treatment groups of both inbred lines in the 1993 and 1994 field tests. The frequency of symptomatic ears was $96 \%$ in both years, but the percent of symptomatic kernels (by weight) per ear was generally higher in 1993, ranging from 26 to $38 \%$, with no significant differences among treatment groups. In 1994, the four treatment groups had 9 to $11 \%$ symptomatic kernels, but results were significantly higher $(24 \%)$ for plants treated with strain A-501 (Table 3).

Fumonisins were found in maize ears from all treatment groups in both field tests. Several fumonisin homologues were detected by the analytical methods, but only levels of fumonisin $\mathrm{B}_{1}$, which was always the predominant homologue, are reported in this study (Table 3). Both symptomless and symptomatic kernel fractions were positive for fumonisin $B_{1}$, and there were no significant differences in frequency of fumonisin-positive samples among treatment groups for either field test. In 1993, mean fumonisin levels in positive samples were 0.3 to $1.0 \mu \mathrm{g} / \mathrm{g}$ in symptomless kernel fractions and 52 to 103 $\mu \mathrm{g} / \mathrm{g}$ in symptomatic kernel fractions; there were no significant differences among treatment groups. In 1994, mean fumonisin levels were more variable among treatments, but differences among treatment groups in mean fumonisin levels of posi- tive samples were not significant, except for heat-treated seed and strain A-501treated seed. The mean content of fumonisin $\mathrm{B}_{1}$ per ear ranged from 48 to 103 $\mu \mathrm{g}$ among treatment groups in 1993, with no significant differences. The mean content of fumonisin $B_{1}$ per ear ranged from 12 to $274 \mu \mathrm{g}$ among four treatment groups in 1994, but was significantly different $(906 \mu \mathrm{g})$ only for plants treated with strain A-501.

When fumonisin data were compared on a treatment group basis, there was no consistent decrease in fumonisin levels following application of fumonisin low-producing strains A-1175 and A-1324. Selected ears from the 1993 field test were then analyzed individually for fumonisin $\mathrm{B}_{1}$ and for the presence of the fumonisin

Table 2. Infection of maize ears and symptomless maize kernels with Fusarium moniliforme and recovery of isolates vegetatively compatible (VC) with applied strains, 1993 and 1994 field tests $^{\mathrm{v}}$

\begin{tabular}{|c|c|c|c|c|c|c|c|c|c|c|c|}
\hline \multirow[b]{2}{*}{ Treatment $^{\mathbf{y}}$} & \multirow{2}{*}{$\begin{array}{c}\text { No. ears } \\
\text { tested }\end{array}$} & \multirow{2}{*}{$\begin{array}{l}\text { Infected } \\
\text { ears }(\%)\end{array}$} & \multicolumn{3}{|c|}{ Ears containing $\mathrm{VC}$ isolates $(\%)^{\mathrm{w}}$} & \multirow{2}{*}{$\begin{array}{c}\text { No. kernels } \\
\text { tested }\end{array}$} & \multirow{2}{*}{$\begin{array}{c}\text { Infected } \\
\text { kernels }(\%)\end{array}$} & \multirow{2}{*}{$\begin{array}{c}\text { No. isolates } \\
\text { tested }\end{array}$} & \multicolumn{3}{|c|}{$\mathrm{VC}$ isolates $(\%)^{\mathrm{x}}$} \\
\hline & & & A-501 & A-1175 & A-1324 & & & & A-501 & A-1175 & A-1324 \\
\hline \multicolumn{12}{|l|}{1993 field test } \\
\hline Heat-treated & 36 & $81 \mathrm{a}$ & $8 \mathrm{~b}$ & $3 b$ & $17 \mathrm{ab}$ & 108 & $56 \mathrm{a}$ & 61 & $8 \mathrm{~b}$ & $2 \mathrm{c}$ & $10 \mathrm{a}$ \\
\hline A-501 & 33 & $85 \mathrm{a}$ & $30 \mathrm{a}$ & $9 \mathrm{~b}$ & $6 \mathrm{~b}$ & 99 & $57 \mathrm{a}$ & 56 & $23 \mathrm{a}$ & $12 \mathrm{~b}$ & $4 \mathrm{a}$ \\
\hline A-1175 & 41 & $85 \mathrm{a}$ & $10 \mathrm{~b}$ & $34 \mathrm{a}$ & $7 \mathrm{~b}$ & 123 & $68 \mathrm{a}$ & 84 & $7 \mathrm{~b}$ & $26 \mathrm{a}$ & $4 \mathrm{a}$ \\
\hline A-1324 & 34 & $82 \mathrm{a}$ & $3 \mathrm{~b}$ & $9 \mathrm{~b}$ & $26 \mathrm{a}$ & 102 & $66 \mathrm{a}$ & 67 & $1 \mathrm{~b}$ & $4 \mathrm{bc}$ & $13 \mathrm{a}$ \\
\hline Total (mean) & 144 & (83) & & & & 432 & $(62)$ & 268 & & & \\
\hline \multicolumn{12}{|l|}{1994 field test } \\
\hline Not treated $\mathrm{d}^{\mathrm{z}}$ & 50 & $62 \mathrm{a}$ & $2 b$ & $0 \mathrm{~b}$ & 2 & 600 & $31 \mathrm{bc}$ & 73 & $1 \mathrm{~b}$ & $0 \mathrm{~d}$ & $1 \mathrm{a}$ \\
\hline Heat-treated & 60 & $77 \mathrm{a}$ & $7 \mathrm{~b}$ & $11 \mathrm{~b}$ & 0 & 720 & $34 \mathrm{c}$ & 88 & $6 \mathrm{~b}$ & $18 \mathrm{~b}$ & $0 \mathrm{a}$ \\
\hline A-501 & 60 & $85 \mathrm{a}$ & $32 \mathrm{a}$ & $8 \mathrm{~b}$ & 0 & 720 & $49 \mathrm{a}$ & 110 & $37 \mathrm{a}$ & $5 \mathrm{c}$ & $0 \mathrm{a}$ \\
\hline A-1175 & 50 & $66 \mathrm{a}$ & $2 b$ & $32 \mathrm{a}$ & 0 & 600 & $26 \mathrm{~b}$ & 75 & $4 \mathrm{~b}$ & $39 \mathrm{a}$ & $0 \mathrm{a}$ \\
\hline A-1324 & 60 & $58 \mathrm{a}$ & $3 \mathrm{~b}$ & $10 \mathrm{~b}$ & 0 & 720 & $21 \mathrm{a}$ & 61 & $3 \mathrm{~b}$ & $23 \mathrm{~b}$ & $0 \mathrm{a}$ \\
\hline Total (mean) & 280 & $(70)$ & & & & 3360 & (33) & 407 & & & \\
\hline
\end{tabular}

${ }^{\vee}$ F. moniliforme infection data are from 3 kernels/ear in 1993 and 12 kernels/ear in 1994. Data for two maize inbred lines were combined.

${ }^{w}$ Percent ears containing isolates vegetatively compatible with strain.

x Percent isolates vegetatively compatible with strain.

y Seeds were treated before planting with hot water to destroy endogenous Fusarium spp., then inoculated with F. moniliforme strains A-501, A-1175, and A-1324. The presence of the applied strains in the kernels was determined by isolation on selected medium followed by vegetative compatibility testing with the applied strains. In each column, numbers followed by the same letter are not significantly different by Chi-square test $(P<0.05)$.

${ }^{\mathrm{z}}$ Inoculated as above, except seeds were not hot-water-treated.

Table 3. Mean weight and fumonisin $B_{1}$ levels of symptomless and symptomatic kernel fractions from individual maize ears, 1993 and 1994 field tests

\begin{tabular}{|c|c|c|c|c|c|c|c|c|c|}
\hline \multirow[b]{2}{*}{ Treatment $^{\mathrm{s}}$} & \multirow{2}{*}{$\begin{array}{c}\text { No. ears } \\
\text { tested }\end{array}$} & \multirow{2}{*}{$\begin{array}{l}\text { Symptomatic } \\
\text { ears }(\%)^{t}\end{array}$} & \multirow{2}{*}{$\begin{array}{l}\text { Symptomatic } \\
\text { kernels }(\%)^{\mathbf{u}}\end{array}$} & \multicolumn{2}{|c|}{ Positive ears (\%) } & \multicolumn{4}{|c|}{ Mean fumonisin $B_{1}^{r}$} \\
\hline & & & & Symptomless & Symptomatic & Symptomless $^{v}$ & ${ }^{{ } \text {Symptomatic }^{\mathrm{w}}}$ & Total $^{x}$ & Symptomatic (\%)y \\
\hline \multicolumn{10}{|l|}{1993 field test } \\
\hline Heat-treated & 13 & 100 & 36 & 54 & 100 & 0.3 & 52 & 1015 & 86 \\
\hline A-501 & 11 & 82 & 26 & 73 & 100 & 0.7 & 91 & 763 & 94 \\
\hline A-1175 & 18 & 100 & 27 & 39 & 100 & 0.5 & 48 & 690 & 97 \\
\hline A-1324 & 11 & 100 & 38 & 82 & 100 & 1.0 & 103 & 1374 & 95 \\
\hline \multicolumn{10}{|l|}{1994 field test } \\
\hline Not treated ${ }^{z}$ & 22 & 100 & $9 \mathrm{~b}$ & 27 & 60 & $2.7 \mathrm{ab}$ & $57 \mathrm{ab}$ & $274 \mathrm{~b}$ & 90 \\
\hline Heat-treated & 25 & 96 & $11 \mathrm{~b}$ & 20 & 53 & $0.8 \mathrm{a}$ & $5 \mathrm{ab}$ & $39 \mathrm{~b}$ & 92 \\
\hline A-501 & 25 & 96 & $24 \mathrm{a}$ & 29 & 80 & $9.4 \mathrm{a}$ & $65 \mathrm{a}$ & $906 \mathrm{a}$ & 82 \\
\hline A-1175 & 25 & 96 & $9 \mathrm{~b}$ & 24 & 80 & $2.4 \mathrm{ab}$ & $39 \mathrm{ab}$ & $226 \mathrm{~b}$ & 87 \\
\hline A-1324 & 12 & 92 & $10 \mathrm{~b}$ & 8 & 50 & $0.7 \mathrm{ab}$ & $6 a b$ & $12 \mathrm{~b}$ & 99 \\
\hline
\end{tabular}

${ }^{\mathrm{q}}$ Percent ears with symptomless and symptomatic kernels that tested positive for fumonisin $\mathrm{B}_{1}$.

${ }^{\mathrm{r}}$ Fumonisin $\mathrm{B}_{1}$ was analyzed by high performance liquid chromatography as described in Materials and Methods, detection limit $=0.05 \mu \mathrm{g} / \mathrm{g}$.

s Seeds were treated before planting with hot water to destroy endogenous Fusarium spp., then inoculated with F. moniliforme strains A-501, A-1175, and A-1324. Data for two maize inbreds were combined. In each column, numbers followed by the same letter are not significantly different by Chi-square test $(P<0.05)$

${ }^{\mathrm{t}}$ Percent ears with symptoms.

u Percent symptomatic kernels per ear (by weight).

${ }^{\mathrm{v}}$ Mean $\mu \mathrm{g} / \mathrm{g}$ in symptomless kernels.

${ }^{\mathrm{w}}$ Mean $\mu \mathrm{g} / \mathrm{g}$ in symptomatic kernels.

${ }^{x}$ Mean total $\mu g$ per ear.

y Mean percent in symptomatic kernels.

${ }^{\mathrm{z}}$ Inoculated as above, except seeds were not hot-water-treated. 
low-producing strain A-1175. Even when the applied strain A-1175 was recovered at a high frequency from both symptomless and symptomatic kernels from an ear of maize, high levels of fumonisin $B_{1}$ could still be detected in that ear (Table 4).

In all treatment groups in both field tests of inbred lines, fumonisin $\mathrm{B}_{1}$ levels were lower in symptomless kernels and higher in symptomatic kernels (Table 3). Over a range of fumonisin $\mathrm{B}_{1}$ content from 0.4 to $6,954 \mu \mathrm{g}$ per ear, 82 to $99 \%$ of the fumonisin $\mathrm{B}_{1}$ in each ear was localized in symptomatic kernels. In addition, $91 \%$ of the fumonisin $B_{1}$ was localized in symptomatic kernels in 7 ears of hybrid maize harvested from border rows of the 1994 field test (data not shown).

\section{DISCUSSION}

The microbiological data presented in this paper indicate a high frequency of infection by $F$. moniliforme in mature maize kernels with and without visible symptoms of disease. Furthermore, the frequency of $F$. moniliforme in symptomless kernels was not significantly increased by seed treatment with this species at planting. These results confirm those reported by other researchers using similar seed inoculation techniques in maize field tests $(11,13,18)$. The frequency of infected kernels and ears was higher in the 1993 field test than in the 1994 field test. This difference may have been due to unusually heavy rains during the spring and summer of 1993, which led to flooding at the Rocky Ford Experimental Farm site. Due to these poor growing conditions, ears harvested in 1993 were of very poor quality: stunted, misshapen, and poorly filled with kernels. In contrast, ears harvested in 1994 were of generally good quality, with few visibly moldy, discolored, or chalky kernels.

In our study, infection with $F$. moniliforme was poorly correlated with fumonisin levels. Symptomless kernel infection was often very high, but fumonisin levels in symptomless kernels were generally low. Thus, our data from individual ears of maize confirm prior observations of a poor correlation between fumonisin levels and the incidence of $F$. moniliforme in bulked maize ears collected from farm households in South Africa $(18,19)$. On the other hand, in our study fumonisin levels in individual ears were highly correlated with visible symptoms, and fumonisin levels were high in symptomatic kernels. Fumonisin levels were similarly low $(<1$ $\mu \mathrm{g} / \mathrm{g})$ in symptomless kernels, and higher in symptomatic kernels $(138 \mu \mathrm{g} / \mathrm{g})$ and cob tissues $(54 \mu \mathrm{g} / \mathrm{g})$ fractionated from a batch of maize screenings associated with an outbreak of leukoencephalomalacia in Arabian horses (20). Thus, removal of diseased or damaged kernels should significantly reduce fumonisin contamination in maize infected with $F$. moniliforme. However, not all diseased and damaged kernels contain high levels of fumonisins, in part because ear rot symptoms can be caused by Fusarium spp. that do not produce fumonisins $(9,17,19)$.

The large number of phenotypic classes possible due to multiple alleles and loci has made genes determining vegetative compatibility useful for studies of the population structure of a number of Fusarium spp. Isolates of $F$. moniliforme from different maize fields, and within individual heterogeneous in vegetative compatibility group profiles $(8,9)$. Thus, vegetative compatibility has been used successfully to distinguish and monitor strains of $F$. moniliforme mating population $\mathrm{A}$ after field release $(7,11,13)$. It should be noted, however, that a vegetative compatibility group is a group of strains that share vegetative compatibility alleles, and thus may comprise closely-related endemic isolates as well as clonal progeny of individual applied strains. The frequency of endemic isolates that share the vegetative compatibility groups of strains A-501, A1175, and A-1324 at the Rocky Ford site was not tested prior to 1993 , but is likely to be low because the applied strains were isolated from maize fields more than 30 miles distant from the test site. Furthermore, analysis of 92 isolates from seedlings 2 weeks after planting, and from stalks 2 months after planting, in 1993 did not find the three applied vegetative compatibility groups in any maize plants to which they had not been applied. In contrast, the applied vegetative compatibility groups of strains A-501, A-1175, and A1324 were recovered from mature kernels of plants throughout the field plots in 1993, and strains A-501 and A-1175 were recovered throughout the field plots in 1994. maize fields, have consistently been very

The occurrence of applied strains in kernels from untreated plants is most likely due to dispersal by wind and rain from the inoculated plants before harvest, and from stalk residues left when the plots were plowed. The 1994 test site was separated from the 1993 test site by $100 \mathrm{~m}$, which may not have been sufficient to prevent aerial dispersal from the 1993 plot.

Although the applied strains A-501 and A-1175 were isolated from untreated plants in both field tests, the frequency of recovery of these strains was significantly higher in treated plants from the same field test. Transmission of strains A-501 and A-1175 from seed to kernel was quite efficient, with more than $30 \%$ of the ears tested yielding these strains in both 1993 and 1994 field tests. The applied strain A-1324 was recovered at low frequency in 1993 and was not recovered in 1994. Transmission of strains A-501 and A-1175 from seed to ear was more efficient in our field tests than in those conducted in Iowa in 1993 and 1994 by Munkvold et al. (13), who found 0 to $10 \%$ of ears infected using the same method of seed inoculation with a spore suspension in the laboratory. The difference between strain recoveries between the 1993 and 1994 Kansas and Iowa field tests is emphasized by the fact that 20 kernels/ear were analyzed in the Iowa tests versus 3 and 12 kernels/ear in 1993 and 1994, respectively, in the Kansas tests. However, Munkvold and Carlton (11) reported improved strain recovery, up to $28 \%$ of ears infected, in 1995 field tests that used a different fungal strain but the same maize hybrid as in their 1994 tests. These differences in strain recovery may be influenced by differences in competitiveness of the pathogen strains or susceptibility of the maize cultivars used.

Table 4. Incidence of fumonisin low-producing strain A-1175 in individual maize ears and its effect on fumonisin levels, 1993 field test $^{\mathrm{v}}$

\begin{tabular}{|c|c|c|c|c|c|}
\hline \multirow[b]{2}{*}{ Ear no. } & \multicolumn{2}{|c|}{ Symptomless kernels } & \multicolumn{2}{|c|}{ Symptomatic kernels } & \multirow[b]{2}{*}{ Content/eary } \\
\hline & $\operatorname{A-1175}(\%)^{\mathrm{w}}$ & Fumonisin $B_{1}{ }^{x}$ & $\operatorname{A-1175}(\%)^{\mathrm{w}}$ & Fumonisin $B_{1}{ }^{x}$ & \\
\hline 1 & 0 & $\mathrm{nd}^{\mathrm{z}}$ & $\mathrm{nt}^{\mathrm{z}}$ & 8 & 56 \\
\hline 2 & 0 & 0.1 & nt & 19 & 84 \\
\hline 3 & 0 & 0.5 & nt & 240 & 4,984 \\
\hline 4 & 0 & 0.9 & nt & 29 & 185 \\
\hline 5 & 33 & 1.2 & 0 & 51 & 781 \\
\hline 6 & 33 & nd & 0 & 39 & 336 \\
\hline 7 & 33 & nd & 0 & 101 & 1,256 \\
\hline 8 & 33 & nd & 0 & 2 & 24 \\
\hline 9 & 67 & 0.2 & 100 & 4 & 27 \\
\hline 10 & 67 & 0.4 & 100 & 31 & 84 \\
\hline 11 & 100 & nd & 100 & 128 & 1,150 \\
\hline
\end{tabular}

${ }^{v}$ Seeds were treated before planting with hot water to destroy endogenous Fusarium spp., then inoculated with $F$. moniliforme strain A-1175. Strain identity was determined by vegetative compatibility with the applied strain A-1175. Strain recovery data are from 3 kernels from symptomatic tissue and 3 kernels from symptomless tissue. Strain recovery in symptomatic kernels was only tested in ears whose symptomless kernels contained the applied strain. Data for two maize inbred lines were combined.

${ }^{\text {w }}$ Percent of tested kernels with strain A-1175.

${ }^{x}$ Measured in $\mu \mathrm{g} / \mathrm{g}$. Fumonisin $\mathrm{B}_{1}$ was analyzed by high performance liquid chromatography as described in Materials and Methods.

${ }^{y}$ Fumonisin $\mathrm{B}_{1}$ content measured in $\mu \mathrm{g}$ per ear.

${ }^{\mathrm{z}} \mathrm{nd}=$ not detected, detection limit $0.05 \mu \mathrm{g} / \mathrm{g}$. $\mathrm{nt}=$ not tested. 
During the 1993 field test, the frequency of recovery of applied stains was highest in 2-week-old seedlings, decreased in stalk tissues of 2-month-old plants, and increased in mature kernels. A similar lower incidence of stalk infection of immature plants by seed-applied strains has also been reported by Munkvold and coworkers $(11,13)$, who also found that strains applied to stalks or silks were more effective than seed-applied strains in colonizing mature kernels. These and other data (14) are consistent with the hypothesis that systemic movement of seed-infecting strains of $F$. moniliforme through maize stalks is enhanced during plant senescence.

Although the fumonisin low-producing strain A-1175 was able to systemically infect maize plants, including both symptomless and symptomatic kernels, there was no consistent decrease in the level of fumonisin $B_{1}$ in kernels from plants treated with this strain. Strain A-1175 may produce high levels of fumonisins under field conditions, although this strain has produced little or no fumonisins when grown on autoclaved maize substrate (16). Alternatively, the frequency of infection with strain A-1175 in our field tests may have been too low for competitive exclusion of naturally occurring strains which typically produce high levels of fumonisins. In field tests where application of an aflatoxin nonproducing strain of Aspergillus flavus decreased aflatoxins in cottonseed, seed infection frequencies with the toxin nonproducing strain up to $100 \%$ have been reported (5). In those tests, the toxin nonproducing strain was applied by spraying plants with a spore suspension or by spreading a colonized wheat grain inoculum on the soil. Munkvold and coworkers $(11,13)$ have also reported an enhanced frequency of kernel infection by spraying ears at silking with a spore suspension of $F$. moniliforme. Experiments are now underway in our laboratories to test alternative inoculation procedures and additional strains of $F$. moniliforme for their potential to reduce fumonisin contamination of maize under field conditions.

\section{ACKNOWLEDGMENTS}

We thank T. Nelsen for the statistical analyses; J. Chlumsky and D. Shane for excellent technical assistance; B. A. Ramundo for field and laboratory assistance; and Holden's Foundation Seeds, Williamsburg, IA, for inbred seed.

\section{LITERATURE CITED}

1. Bennett, G. A., Wicklow, D. T., Caldwell, R. W., and Smalley, E. G. 1988. Distribution of trichothecenes and zearalenone in Fusarium graminearum: rotted corn ears grown in a controlled environment. J. Agric. Food Chem. 36:639-642.

2. Chu, F. S., and Li, G. Y. 1994. Simultaneous occurrence of fumonisin $B_{1}$ and other mycotoxins in moldy corn collected from the People's Republic of China in regions high in esophageal cancer. Appl. Environ. Microbiol. 60:847-852.

3. Coker, R. D., Nagler, M. J., Blunden, G., Sharkey, A. J., Defize, P. R., Derksen, G. B., and Whitaker, T. B. 1995. Design of sampling plans for mycotoxins in foods and feeds. Nat. Toxins 3:257-262.

4. Correll, J. C., Klittich, C. J. R., and Leslie, J. F. 1987. Nitrate nonutilizing mutants of Fusarium oxysporum and their use in vegetative compatibility tests. Phytopathology 77:1640-1646.

5. Cotty, P. J. 1994. Influence of field application of an atoxigenic strain of Aspergillus flavus on the populations of A. flavus infecting cotton bolls and on the aflatoxin content of cottonseed. Phytopathology 84:12701277.

6. Daniels, B. A. 1983. Elimination of Fusarium moniliforme from corn seed. Plant Dis. 67:609-611.

7. Kedera, C. J., Leslie, J. F., and Claflin, L. E. 1994. Genetic diversity of Fusarium section Liseola (Gibberella fujikuroi) in individual maize stalks. Phytopathology 84:603-607.

8. Leslie, J. F. 1995. Gibberella fujikuroi: available populations and variable traits. Can. J. Bot. (Suppl. 1) 73:S282-S291.

9. Leslie, J. F., Doe, F. J., Plattner, R. D., Shackelford, D. D., and Jonz, J. 1992. Fumonisin B 1 production and vegetative compatibility of strains from Gibberella fujikuroi mating population "A" (Fusarium moniliforme). Mycopathologia 117:37-45.

10. Leslie, J. F., Plattner, R. D., Desjardins, A. E., and Klittich, C. J. R. 1992. Fumonisin $\mathrm{B}_{1}$ production by strains from different mating populations of Gibberella fujikuroi (Fusarium section Liseola). Phytopathology 82:341-345.

11. Munkvold, G. P., and Carlton, W. M. 1997. Influence of inoculation methods on systemic
Fusarium moniliforme infection of maize plants grown from infected seeds. Plant Dis. 81:211-216.

12. Munkvold, G. P., and Desjardins, A. E. 1997. Fumonisins in maize, can we reduce their occurrence? Plant Dis. 81:556-565.

13. Munkvold, G. P., McGee, D. C., and Carlton, W. M. 1997. Importance of different pathways for maize kernel infection by Fusarium moniliforme. Phytopathology 87:209-217.

14. Nelson, P. E. 1992. Taxonomy and biology of Fusarium moniliforme. Mycopathologia 117:29-36.

15. Nelson, P. E., Toussoun, T. A., and Marasas, W. F. O. 1983. Fusarium Species: an Illustrated Manual for Identification. The Pennsylvania State University Press, University Park and London.

16. Plattner, R. D., Desjardins, A. E., Leslie, J. F., and Nelson, P. E. 1996. Identification and characterization of strains of Gibberella fujikuroi mating population A with rare fumonisin production phenotypes. Mycologia 88:416-424.

17. Reid, L. M., Mather, D. E., and Hamilton, R. I. 1996. Distribution of deoxynivalenol in Fusarium graminearum-infected maize ears. Phytopathology 86:110-114.

18. Rheeder, J. P., Marasas, W. F. O., Thiel, P. G., Sydenham, E. W., Shephard, G. S., and van Schalkwyk, D. J. 1992. Fusarium moniliforme and fumonisins in corn in relation to human esophageal cancer in Transkei. Phytopathology 82:353-357.

19. Rheeder, J. P., Sydenham, E. W., Marasas, W. F. O., Thiel, P. G., Shephard, G. S., Stockenstrom, S., Cronje, D. W., and Viljoen, J. H. 1995. Fungal infestation and mycotoxin contamination of South African commercial maize harvested in 1989 and 1990. S. Afr. J. Sci. 91:127-131.

20. Ross, P. F., Rice, L. G., Plattner, R. D., Osweiler, G. D., Wilson, T. M., Owens, D. L. Nelson, H. A., and Richard, J. L. 1991. Concentrations of fumonisin $B_{1}$ in feeds associated with animal health problems. Mycopathologia 114:129-135.

21. Scott, G. E., and Zummo, N. 1995. Size of maize sample needed to determine percent kernel infection by Aspergillus flavus. Plant Dis. 79:861-864.

22. Shephard, G. S., Thiel, P. G., Stockenstrom, S., and Sydenham, E. W. 1996. Worldwide survey of fumonisin contamination of corn and corn-based products. J. AOAC Int. 79:671-687.

23. Sydenham, E. W., Shephard, G. S., and Thiel, P. G. 1992. Liquid chromatographic determination of fumonisins $B_{1}, B_{2}$, and $B_{3}$ in foods and feeds. J. AOAC Int. 75:313-318. 